\title{
Longitudinal Effects of Personality Disorders on Psychosocial Functioning of Patients With Major Depressive Disorder
}

\author{
John C. Markowitz, M.D.; Andrew E. Skodol, M.D.; Eva Petkova, Ph.D.; \\ Jianfeng Cheng, Ph.D.; Charles A. Sanislow, Ph.D.; Carlos M. Grilo, Ph.D.; \\ John G. Gunderson, M.D.; and Thomas H. McGlashan, M.D.
}

\begin{abstract}
Objective: No previous research has focused on psychosocial functioning in understanding how personality disorders compound the impairment caused by major depressive disorder over time. This report describes the effects of persistent and remitting comorbid personality disorders on the depressive status and functioning of patients with major depressive disorder over the course of 2 years.
\end{abstract}

Method: Longitudinal data on functioning from the first 2 years of the Collaborative Longitudinal Personality Disorders Study were evaluated for 3 groups of subjects with major depressive disorder: subjects with major depressive disorder alone $(\mathrm{N}=103)$, those with persistent comorbid personality disorders $(\mathrm{N}=164)$, and those with comorbid personality disorders that remitted $(\mathrm{N}=69)$. DSM-IV criteria were used for mood and personality disorder diagnoses. The data were gathered from September 1996 to August 2000 and from September 2001 to September 2004.

Results: Subjects whose personality disorders remitted were more likely than those with persisting personality disorders to have major depressive disorder remit. Social functioning, as measured by the Longitudinal Interval Follow-up Evaluation and the Global Assessment of Functioning, improved across a range of domains over time, with most gains occurring in the first 6 months of follow-up and with differential improvement by group. As hypothesized, subjects whose personality disorders remitted fared nearly as well as did subjects without personality disorders, whereas subjects whose personality disorders persisted functioned most poorly.

Conclusions: Outcome research on major depressive disorder has often ignored Axis II disorders. Our data indicate that the longitudinal course of personality psychopathology meaningfully influences depressive outcome and psychosocial functioning in patients with major depressive disorder. The findings indicate the need to target both symptom relief and psychosocial functioning and to treat both personality and mood disorders in comorbid patients.

(J Clin Psychiatry 2007;68:186-193)
Received April 13, 2006; accepted June 26, 2006. From the Department of Personality Studies (Drs. Markowitz and Skodol) and the Department of Biostatistics (Drs. Petkova and Cheng), New York State Psychiatric Institute, New York; the Yale Psychiatric Research Institute and Yale University, New Haven, Conn. (Drs. Sanislow, Grilo, and McGlashan); and the Department of Psychiatry, Harvard Medical School, Cambridge, Mass. (Dr. Gunderson).

Supported in part by an Independent Investigator Award from the National Alliance for Research on Schizophrenia and Depression (Dr. Markowitz) and National Institute of Mental Health grant numbers RO1 MH 01654, 50837, 50838, 50839, 50840, 50850, and 73708 .

The authors report no additional financial or other relationship relevant to the subject of this article.

This manuscript has been reviewed and approved for submission by the Publications Committee of the Collaborative Longitudinal Personality Disorder Study.

Corresponding author and reprints: John C. Markowitz, M.D. Department of Personality Studies, New York State Psychiatric Institute, 1051 Riverside Dr., Unit \#129, New York, NY 10032 (e-mail:jcm42@columbia.edu).

$\mathbf{P}$ sychiatric epidemiology and treatment studies have focused more on diagnoses and symptoms than on related domains such as psychosocial functioning. In the extant literature, both major depressive disorder (MDD) $)^{1-3}$ and personality disorders ${ }^{4}$ have been shown to independently and persistently impair social and occupational functioning. Indeed, functional impairment helps to define these disorders in DSM-IV-TR. Treatment and observational studies of depression and personality disorders that have addressed functioning tend to show that improvement in social role lags behind symptomatic improvement. ${ }^{4,5}$ A principle underlying interpersonal psychotherapy for depression ${ }^{6}$ is that symptoms impair functioning and poor functioning worsens demoralization and symptoms, creating a potentially vicious cycle.

Much of the literature addressing the relationship between depression and functioning has ignored personality disorders. Neither Judd and colleagues, ${ }^{1}$ in reviewing 10 years of longitudinal data from the National Institute for Mental Health (NIMH) Collaborative Depression Study, nor Ormel and colleagues, ${ }^{2}$ in assessing depression and anxiety in primary care patients over 3.5 years, considered the potential moderating effects of personality disorders on psychosocial disability. Nor did a more recent, 3-year study by Ormel et al., ${ }^{7}$ despite its mention of "trait 
effects" in MDD patients (evaluated by comparing impairment of remitted MDD subjects with impairment of those who never had a depressive episode).

Skodol and colleagues ${ }^{4}$ in the Collaborative Longitudinal Personality Disorders Study (CLPS) found little improvement in psychosocial functioning among subjects $(\mathrm{N}=668)$ with personality disorders followed for 2 years, whereas subjects with MDD but no personality disorder showed gains in some psychosocial domains. In that study, Skodol et al. did not, however, assess the effect of comorbid personality disorders on major depression. In a more recent, cross-sectional study, they did find that patients with MDD who had persistent personality psychopathology had greater impairment in functioning and poorer general health perception on the Medical Outcomes Study SF- $36^{8}$ than those without personality disorders. ${ }^{9}$ Studying the interactive effects of mood and personality disorders on functioning over time may contribute to our understanding of the two disorders and of the patients who not infrequently suffer from both. Such research might also lead to more effective treatment of comorbid patients.

All recent studies of personality disorders in patients ${ }^{10,11}$ and of personality disorder features in nonpatients ${ }^{12}$ and community subjects ${ }^{13}$ have shown improvement in personality disorder psychopathology over time. Thus, the examination of patients whose personality disorders persist in comparison to those whose remit is justified. Using data from CLPS, we investigated the longitudinal effect of persisting versus remitting personality disorder and MDD on psychosocial functioning.

The ongoing, multisite CLPS tracks the course of subjects with one of 4 personality disorders and a comparison group of subjects with MDD but no personality disorder. Since many subjects who were enrolled because of Axis II diagnoses also had comorbid MDD, this large, welldiagnosed sample offered an opportunity to assess the effect on functioning of the courses of personality disorders, MDD, and their interaction. Grilo et al., ${ }^{14}$ reporting on 302 CLPS subjects with comorbid MDD and personality disorders, found a $73.5 \%$ remission of MDD, with little difference by gender. Subjects with schizotypal, borderline, or avoidant index personality disorders had a significantly longer time to MDD remission than did subjects without a personality disorder.

Using data from the first 2 years of the CLPS cohort, we contrasted (1) subjects with baseline MDD who also had stable, nonremitting personality disorders over the course of 2 years (denoted MDD/PD-NR, for nonremitting personality disorders), (2) subjects with baseline MDD and with baseline personality disorders that remitted over time (MDD/PD-R, for remitted), and (3) patients with baseline MDD but no personality disorder diagnosis (MDD/noPD).

Based on the presumption that comorbid symptom severity is additive if not synergistic, and that personality disorder symptoms would compound those of depression, we hypothesized that (1) MDD/PD-R (remitting personality disorder) subjects would be more likely to have MDD remit than MDD/PD-NR (nonremitting personality disorder) subjects; (2) MDD/noPD subjects would have the best course; (3) MDD/PD-NR subjects would have the worst social/occupational functioning over time, relative to the other cohorts; and (4) MDD/PD-R subjects would have improved social/occupational functioning (whether or not MDD remitted), approaching the levels of subjects with MDD/noPD.

\section{METHOD}

\section{Description of CLPS Cohort}

The CLPS study sample comprises subjects aged 18 to 45 years, recruited at Brown, Columbia, Harvard, and Yale University medical schools, and diagnosed by experienced clinical interviewers trained to reliability on the Structured Clinical Interview for DSM-IV Axis I Disorders-Patient Version (SCID-I/P) ${ }^{15}$ and the Diagnostic Interview for DSM-IV Personality Disorders (DIPDIV). ${ }^{16}$ The CLPS recruited subjects with one of 4 personality disorders-schizotypal, borderline, avoidant, or obsessive-compulsive-and subjects with MDD but no Axis II diagnosis. The CLPS sample, a sample of convenience, has grown over time, with the addition of an enriched minority sample, from 668 subjects to a total of 733. This report includes data from the latter, full sample. The initial data were gathered from September 1996 to August 2000, and the data for the enriched sample were gathered from September 2001 to September 2004. Although the CLPS targeted 4 personality disorders, rates of diagnostic co-occurrence have been found to resemble those of other clinical samples. ${ }^{17}$ Subjects were in uncontrolled treatments in this naturalistic follow-along study. Subjects with personality disorders had more extensive treatment histories than did subjects with MDD alone. ${ }^{18}$

\section{Subjects}

This subsample of the larger cohort included all CLPS subjects with baseline MDD $(\mathrm{N}=336)$, with or without personality disorders: 36 with an index diagnosis of schizotypal, 77 with borderline, 69 with avoidant, and 51 with obsessive-compulsive personality disorder, as well as the 103 subjects with MDD but no personality disorder.

\section{Assessments}

Subjects were followed longitudinally, rated after 6 months, 1 year, and 2 years. Serial assessments included the DIPD-IV at baseline and its modified, follow-along version (DIPD-FAV) ${ }^{16}$ for Axis II disorders at 6 months, 1 year, and 2 years and the SCID-I/ $\mathrm{P}^{15}$ at baseline and subsequently the Longitudinal Interval Follow-up Evaluation (LIFE) ${ }^{19}$ for Axis I disorders and social functioning. Kappas for interrater reliability were 0.80 for current 
MDD on the SCID and ranged from 0.58 to 1.0 for personality disorders on the DIPD-IV. ${ }^{20}$

Social and occupational functioning were rated monthly, using LIFE psychosocial scales. The LIFE psychosocial scales assessed employment; interactions with friends, spouse or mate, and parents; recreation; global social adjustment; and the DSM-IV Axis V Global Assessment of Functioning (GAF). ${ }^{22}$ Most areas of functioning are rated on 5 -point severity scales ranging from $1=$ no impairment, high level or very good functioning; $2=$ no impairment, satisfactory or good functioning; $3=$ mild impairment or fair functioning; $4=$ moderate impairment or poor functioning; and $5=$ severe impairment or very poor functioning. The reliability of these ratings has been established. ${ }^{19,21}$ The GAF is a 100-point scale wherein 100 indicates the optimal level of functioning. ${ }^{22}$ More detailed descriptions of the CLPS study design and assessments have been published elsewhere. ${ }^{17,20,23}$

\section{Remission}

Remission from MDD was defined by a rating of $<2$ (1 or 2 symptoms of mild degree with no impairment in functioning) for 8 consecutive weeks on the weekly (retrospective) Psychiatric Status Rating (PSR) scores for MDD using the LIFE. ${ }^{19}$ This followed precedent in numerous previous studies. ${ }^{9,10,14}$ As a still more stringent test, secondary analyses used a PSR score of 1 (no symptoms) to define depressive remission. Remission from personality disorders was defined by interview using the DIPD-IV-FAV, ${ }^{16}$ with which the traits and behaviors indicative of each criterion for the 4 personality disorders are rated for each month of the follow-up interval. We defined remission in 2 ways, requiring 2 or fewer criteria present for 2 consecutive months and for 12 consecutive months. As few differences appeared using the 2- and 12-month definitions, we report the latter.

\section{Statistics}

The 3 groups (MDD/noPD, MDD/PD-R, and MDD/ PD-NR) were compared on demographic characteristics using analysis of variance or $\chi^{2}$ tests for independence as appropriate. The groups were compared with respect to time to MDD remission using the log-rank test (on $2 \mathrm{df}$ ). ${ }^{24}$ Evidence that the groups were not equivalent was judged at level $\alpha=.05$; a significant overall test was followed by pairwise comparisons between groups based on log-rank tests (1 df). Unadjusted $\mathrm{p}$ values are reported.

The comparison of the effects of time course on functioning across the 3 groups was based on mixed-effects models for longitudinal data, ${ }^{25}$ individually for each functioning measure, as it was unclear that group differences were similar for all outcomes. Repeated assessment of each functioning measure was modeled as a function of group, time, and group-by-time interaction. The variable time was treated as a factor with 4 levels (baseline and 6,
12, and 24 months) to allow for nonlinear course of symptom change over time. First, the model for the covariance of the repeated observations was selected based on Bayesian Information Criteria, ${ }^{26}$ choosing among unstructured, first order autoregressive (AR[1]), and compound symmetry. ${ }^{27}$ Modeling the mean response followed the selection of the covariance model. The significance of the overall interaction term $[F$ test with $(3-1) \times(4-1)=6 \mathrm{df}$ for the numerator] was judged at level $\alpha=.05$. Presence of a significant interaction term was interpreted to indicate that changes over time differed between groups and was followed by pairwise comparisons between groups at each time point; unadjusted $\mathrm{p}$ values are reported. If the interaction term was not significant, a model with only main effects for group and time was fitted and inference regarding differences between groups relies on this model, with significance of the main effects judged at $\alpha=.05$. If the main effect for group was significant, pairwise comparisons between groups were performed (with identical contrasts at all time points); unadjusted $\mathrm{p}$ values are reported. To assess the effect of MDD remission during the course of 2 years on inferences about group differences in functioning over time, the analyses described above were repeated adjusting for presence/absence of MDD (a time-varying indicator variable). These analyses were also used to assess the effect of MDD remission on functioning. The models described above were fit using PROC MIXED in SAS.

\section{RESULTS}

Of 248 CLPS subjects with an index personality disorder, $98(39.5 \%)$ had personality disorder remit during the 2 -year period. Table 1 provides a demographic description of the 3 groups under study. There were no significant demographic differences among the 3 groups.

\section{MDD Remission}

Rates of remission for MDD by group using a PSR threshold of $<2$ were $85.4 \%$ (88/103) for MDD/noPD, $76.8 \%$ (53/69) for MDD/PD-R, and 63.4\% (104/164) for $\mathrm{MDD} / \mathrm{PD}-\mathrm{NR}(\log -\mathrm{rank}=24.6, \mathrm{df}=2, \mathrm{p}<.0001)$. Subjects with a remitting personality disorder were more likely than those with a persisting personality disorder to have MDD remit $(\log$-rank $=6.72, \mathrm{df}=1, \mathrm{p}=.01)$, supporting hypothesis 1 . There was no significant difference in depressive remission rates between the $\mathrm{MDD} / \mathrm{noPD}$ and MDD/PD-R groups (log-rank $=2.32, \mathrm{df}=1, \mathrm{p}=.16$ ). Figure 1 illustrates that most remissions occurred relatively early in the study.

Analyses using the PSR cutoff of 1 magnified these between-group findings. Remission rates in the 3 groups were $80.6 \%$ for $\mathrm{MDD} / \mathrm{noPD}$, $68.1 \%$ for $\mathrm{MDD} / \mathrm{PD}-\mathrm{R}$, and $48.2 \%$ for MDD/PD-NR (log-rank $=35.9, \mathrm{df}=2, \mathrm{p}<$ .0001). Similar differences remained between the MDD/ PD-R and MDD/PD-NR groups $(\log$-rank $=11.5, \mathrm{df}=1$, 


\begin{tabular}{|c|c|c|c|c|c|c|}
\hline \multirow[b]{3}{*}{ Variable } & \multirow[b]{3}{*}{$\begin{array}{l}\text { MDD/noPD } \\
(\mathrm{N}=103)\end{array}$} & \multirow[b]{3}{*}{$\begin{array}{l}\text { MDD/PD-R } \\
(\mathrm{N}=69)\end{array}$} & \multirow[b]{3}{*}{$\begin{array}{c}\text { MDD/PD-NR } \\
(\mathrm{N}=164)\end{array}$} & \multirow{2}{*}{\multicolumn{3}{|c|}{ Statistics }} \\
\hline & & & & & & \\
\hline & & & & $\begin{array}{c}\text { Test } \\
\text { Result }\end{array}$ & df & $\mathrm{p}$ Value \\
\hline Age, mean (SD), y & $32.8(8.0)$ & $33.6(8.6)$ & $33.3(8.0)$ & $F=0.22$ & 1 & .64 \\
\hline Gender, female/male, $\%$ & $61.2 / 38.8$ & $62.3 / 37.7$ & $68.3 / 31.7$ & $\chi^{2}=1.66$ & 2 & .44 \\
\hline Ethnicity, \% & & & & $\chi^{2}=3.96$ & 6 & .76 \\
\hline White & 68.9 & 68.1 & 60.4 & & & \\
\hline African American & 17.5 & 15.9 & 20.1 & & & \\
\hline Hispanic & 10.7 & 13.0 & 17.1 & & & \\
\hline Asian/other & 2.9 & 2.9 & 2.4 & & & \\
\hline
\end{tabular}

Figure 1. Major Depressive Disorder Remission Among Patients With Remitted, Nonremitted, or No Personality Disorder

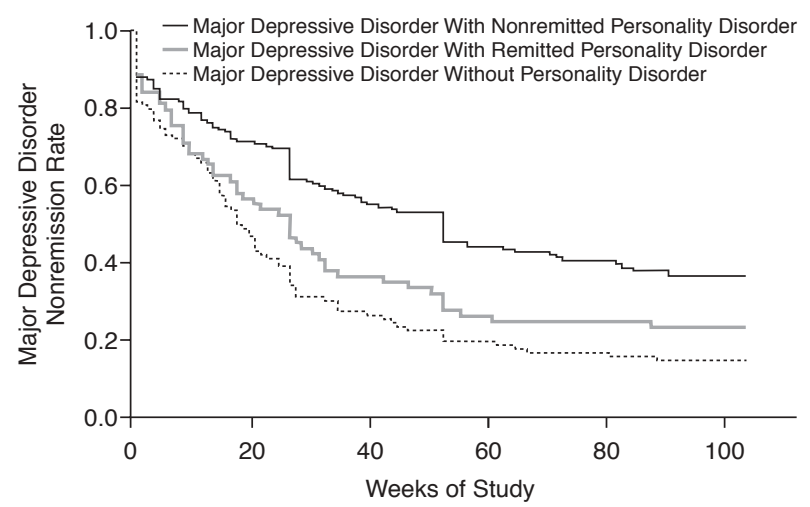

$\mathrm{p}=.007)$ and between the MDD/noPD and MDD/PD-R groups $(\log$-rank $=2.5, \mathrm{df}=1, \mathrm{p}=.12)$.

\section{Social and Occupational Functioning}

The temporal effects of diagnostic remission status on psychosocial functioning were the central concern of the study. Table 2 and Figure 2 illustrate that social and occupational functioning improved over time across groups, albeit modestly in some instances, and between groups. Most gains appeared in the first 6 months, with some further progress over the rest of the 2-year interval. The largest absolute improvements in functioning appeared in the MDD/PD-R group.

Table 3 displays a longitudinal analysis of change in functional impairment over time, modeled for the 3 diagnostic groups. There were significant effects for time and group for all of the functional variables. Overall, MDD/noPD subjects, as anticipated, functioned better than MDD/PD-R subjects, while MDD/PD-NR subjects fared the worst. By the end of the 2-year interval, however, the MDD/PD-R subjects, their personality disorders having remitted, had largely caught up with the $\mathrm{MDD} /$ noPD subjects in psychosocial functioning, while the MDD/PD-NR subjects lagged behind both of those groups.

Employment. There were effects for improvement over time (treated as a categorical variable) and by group. Each diagnostic group began and ended with significantly different functioning (MDD/noPD > MDD/ $\mathrm{PD}-\mathrm{R}>\mathrm{MDD} / \mathrm{PD}-\mathrm{NR})$. There were no time-by-group interactions.

Friendship. Results were similar to those for employment.

Spouse. Many subjects were not married: this analysis comprised only $101(28.8 \%)$ of the baseline sample. There was again statistically significant improvement with time and by group, following the same MDD/ noPD > MDD/PD-R > MDD/PD-NR pattern.

Parent. There were general effects for time and for group. All groups showed improvement over time, but relationship to parents was better at all points for the MDD/ noPD subjects than for the 2 personality-disordered groups, which were not statistically distinguishable.

Recreation. This variable showed group ordering and time effects similar to those for employment, friendship, and spousal functioning.

Social. This variable and the GAF both cover global social functioning. Unlike the GAF, which incorporates symptom severity, the LIFE social adjustment subscale is specific to social and occupational functioning. Both variables showed effects for group and time as well as time-by-group interactions. The LIFE social variable at baseline showed MDD/noPD > MDD/PD-R = MDD/ PD-NR. At 6 months, MDD/PD-R subjects did not statistically differ from MDD/noPD subjects, and both functioned better than MDD/PD-NR subjects. This pattern persisted at 12 and 24 months: MDD/PD-R subjects had caught up with the MDD/noPD subjects, whereas MDD/ PD-NR subjects lagged behind.

$\boldsymbol{G A} \boldsymbol{F}$. GAF scores rose over time, with most of the gains in the first 6 months. After 2 years, MDD/noPD subjects had improved by a mean 4.6 points, compared to 9.9 for MDD/PD-R and 1.1 for MDD/PD-NR subjects. Thus, subjects in the MDD/PD-NR group showed no 


\begin{tabular}{|c|c|c|c|c|c|c|c|c|c|}
\hline \multirow[b]{2}{*}{ Variable } & \multicolumn{3}{|c|}{ MDD/noPD } & \multicolumn{3}{|c|}{ MDD/PD-R } & \multicolumn{3}{|c|}{ MDD/PD-NR } \\
\hline & $\mathrm{N}$ & Mean & $\mathrm{SD}$ & $\mathrm{N}$ & Mean & SD & $\mathrm{N}$ & Mean & SD \\
\hline \multicolumn{10}{|c|}{ Employment } \\
\hline $0 \mathrm{mo}$ & 75 & 2.68 & 1.43 & 54 & 3.31 & 1.60 & 100 & 3.74 & 1.39 \\
\hline $6 \mathrm{mo}$ & 67 & 1.87 & 1.06 & 43 & 1.98 & 1.16 & 77 & 2.40 & 1.27 \\
\hline $12 \mathrm{mo}$ & 73 & 1.85 & 1.11 & 40 & 1.90 & 0.98 & 81 & 2.15 & 1.11 \\
\hline $24 \mathrm{mo}$ & 65 & 1.69 & 0.95 & 51 & 1.88 & 1.13 & 82 & 2.33 & 1.32 \\
\hline \multicolumn{10}{|l|}{ Friendship } \\
\hline $0 \mathrm{mo}$ & 103 & 2.50 & 1.04 & 69 & 2.94 & 1.34 & 164 & 3.41 & 1.19 \\
\hline $6 \mathrm{mo}$ & 100 & 2.24 & 1.13 & 69 & 2.81 & 1.28 & 163 & 3.21 & 1.22 \\
\hline $12 \mathrm{mo}$ & 100 & 2.21 & 1.02 & 69 & 2.52 & 1.04 & 160 & 3.09 & 1.18 \\
\hline $24 \mathrm{mo}$ & 94 & 1.86 & 0.92 & 68 & 2.34 & 1.07 & 150 & 2.93 & 1.15 \\
\hline \multicolumn{10}{|l|}{ Spouse } \\
\hline $0 \mathrm{mo}$ & 30 & 2.43 & 1.28 & 19 & 2.58 & 1.43 & 52 & 3.33 & 1.10 \\
\hline $6 \mathrm{mo}$ & 30 & 2.27 & 1.39 & 19 & 2.16 & 1.30 & 52 & 3.15 & 1.11 \\
\hline $12 \mathrm{mo}$ & 29 & 2.17 & 1.34 & 15 & 2.87 & 0.74 & 49 & 3.02 & 1.31 \\
\hline $24 \mathrm{mo}$ & 27 & 1.89 & 1.12 & 15 & 1.93 & 0.96 & 40 & 2.60 & 1.43 \\
\hline \multicolumn{10}{|l|}{ Parent } \\
\hline $0 \mathrm{mo}$ & 99 & 2.53 & 1.08 & 65 & 2.69 & 1.32 & 146 & 3.08 & 1.34 \\
\hline $6 \mathrm{mo}$ & 94 & 2.28 & 1.07 & 65 & 2.62 & 1.14 & 145 & 2.88 & 1.23 \\
\hline $12 \mathrm{mo}$ & 95 & 2.16 & 0.96 & 63 & 2.52 & 0.98 & 141 & 2.75 & 1.15 \\
\hline $24 \mathrm{mo}$ & 89 & 2.24 & 1.08 & 61 & 2.38 & 1.07 & 133 & 2.61 & 1.11 \\
\hline \multicolumn{10}{|l|}{ Recreation } \\
\hline $0 \mathrm{mo}$ & 103 & 2.96 & 1.07 & 69 & 3.36 & 1.08 & 163 & 3.68 & 1.09 \\
\hline $6 \mathrm{mo}$ & 100 & 2.41 & 1.22 & 69 & 2.64 & 1.12 & 164 & 3.32 & 1.15 \\
\hline $12 \mathrm{mo}$ & 100 & 2.23 & 0.95 & 69 & 2.49 & 1.04 & 159 & 3.26 & 1.23 \\
\hline $24 \mathrm{mo}$ & 94 & 2.11 & 1.10 & 68 & 2.16 & 1.03 & 150 & 3.07 & 1.30 \\
\hline \multicolumn{10}{|l|}{ Social } \\
\hline $0 \mathrm{mo}$ & 103 & 3.41 & 0.85 & 69 & 3.99 & 0.87 & 164 & 4.08 & 0.74 \\
\hline $6 \mathrm{mo}$ & 100 & 2.88 & 1.04 & 69 & 3.00 & 1.10 & 164 & 3.77 & 0.92 \\
\hline $12 \mathrm{mo}$ & 100 & 2.76 & 1.06 & 69 & 3.00 & 1.18 & 160 & 3.79 & 0.89 \\
\hline $24 \mathrm{mo}$ & 94 & 2.67 & 0.99 & 68 & 2.74 & 1.07 & 150 & 3.66 & 0.93 \\
\hline \multicolumn{10}{|l|}{ GAF } \\
\hline 0 mo & 103 & 61.0 & 10.0 & 69 & 55.3 & 8.5 & 164 & 52.4 & 9.3 \\
\hline $6 \mathrm{mo}$ & 100 & 66.5 & 11.4 & 69 & 63.5 & 11.0 & 164 & 55.2 & 11.1 \\
\hline $12 \mathrm{mo}$ & 100 & 67.4 & 12.6 & 69 & 63.3 & 12.4 & 160 & 55.0 & 10.5 \\
\hline $24 \mathrm{mo}$ & 94 & 65.6 & 12.3 & 68 & 65.1 & 13.6 & 150 & 53.3 & 11.8 \\
\hline $\begin{array}{c}\text { Abbreviat } \\
\text { Follow- } \\
\text { personal } \\
\text { personal } \\
\text { disorder. }\end{array}$ & $\mathrm{AF}=$ & obal $A$ & $\mathrm{Ds}=\mathrm{r}$ & & tioning & $\begin{array}{l}\mathrm{FE}=\mathrm{I} \\
\text { rder } \mathrm{y}\end{array}$ & ngitu & $\begin{array}{l}\text { al Inter } \\
\text { norbid } \\
\text { nitted }\end{array}$ & \\
\hline
\end{tabular}

clinically meaningful change over the 2 years. At baseline, MDD/noPD subjects had higher GAF scores than the 2 personality disorder groups, which did not differ. At 6 months, the MDD/PD-R subjects occupied a middle terrain, statistically separate from the other 2 groups. This pattern persisted at the 12-month evaluation. At 24 months, however, subjects whose personality disorder had remitted were indistinguishable from those who had never had a personality disorder, with both superior to the MDD/PD-NR group.

The GAF score range from 61 to 69 comprises "some mild symptoms (e.g., depressed mood and mild insomnia) OR some difficulty in social, occupation, or school functioning ... but generally functioning pretty well, has some meaningful interpersonal relationships." $22(\mathrm{p47)}$ This is where the MDD/noPD subjects began and ended, and where the MDD/PD-R subjects eventually arrived. By contrast, the MDD/PD-NR cohort remained throughout squarely in the low 50s, a range describing "moderate symptoms (e.g., flat affect and circumstantial speech, occasional panic attacks) OR moderate difficulty in social, occupation, or school functioning (few friends, conflicts with peers or coworkers)." $22(\mathrm{p} 47)$

\section{Role of MDD Remission}

Adjusting for presence or absence of MDD at each time point did not qualitatively change the inferences about group differences in course of functioning outcomes. The effect of presence or absence of MDD on all functioning outcome measures was statistically significant except for the measure Parent. The magnitude of the effect was $(-8.63$ [0.56]) for GAF and varied between 0.09 and 0.82 on LIFE functioning scales.

\section{DISCUSSION}

Tracking the social and occupational functioning of depressed subjects over the course of 2 years revealed 
Figure 2. Plot of Model-Based (A) Global Social Adjustment and (B) Global Assessment of Functioning

A.

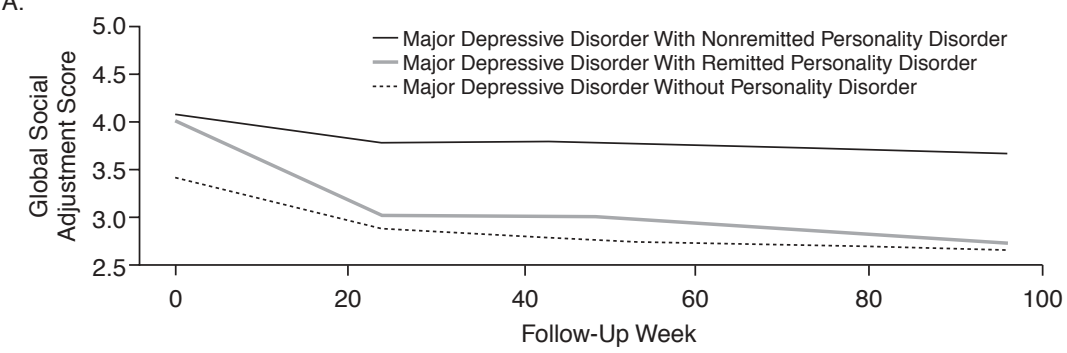

B.

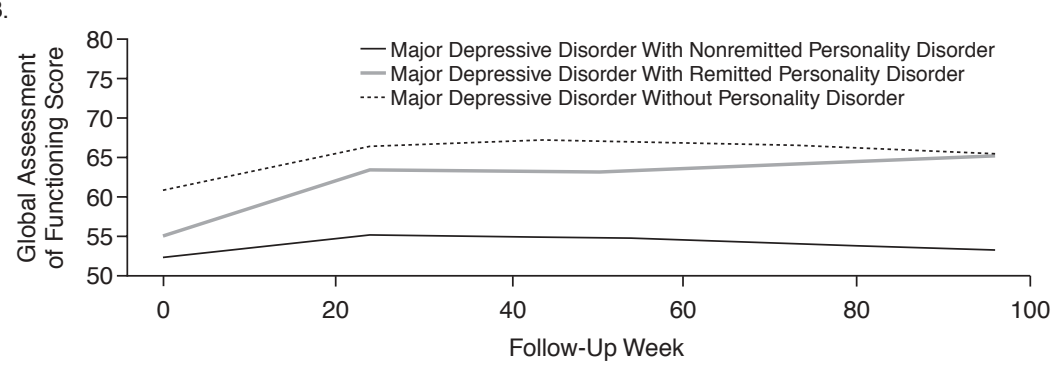

important effects of the status of comorbid personality disorders. The study hypotheses were confirmed: the presence of a persistent personality disorder influenced both the likelihood of remission from a major depressive episode and the severity of the depressed person's impairment in psychosocial functioning. When personality disorders remitted, MDD was more likely to remit and social and occupational functioning were more likely to improve. Major depressive disorder also impaired social and occupational functioning (except with parents), but adjusting for MDD did not explain the effect of personality disorders. Moreover, subjects whose personality disorders remitted showed the largest absolute gains in functioning and were likely to "catch up" over 2 years to levels of social functioning approaching those of subjects who had had no personality disorders at baseline.

Despite the substantial numbers of personality disorder remissions observed in the study, the latent variables underlying both personality traits and personality disorders have been demonstrated to have considerable ordinal stability over the same 2 -year period. ${ }^{28}$

The findings suggest that all subjects are impaired across psychosocial categories, as might be expected for individuals with MDD. The presence of a personality disorder compounded those burdens, but only if the personality disorder itself did not remit over the course of the 2 years. On the whole, the MDD/PD-NR group had the worst baseline scores across areas of social functioning, whereas subjects without personality disorders at baseline reported milder, if still pathologic, dysfunction.

Most, albeit not all, treatment outcome studies of MDD that have considered Axis II have found that personality disorders negatively influence symptomatic response. ${ }^{29-34}$ Functional outcome has rarely been examined. One exception is the analysis by Shea and colleagues ${ }^{35}$ of data from the NIMH Treatment of Depression Collaborative Research Program involving a clinician-rated scale of personality pathology rather than a diagnostic, semistructured interview. They showed that presence of personality pathology worsened outcome of antidepressant treatment in terms of symptoms and psychosocial functioning.

Poor symptomatic outcomes make clinical sense because personality disorders compound the overall symptom burden of depressed individuals: a history of panic disorder, ${ }^{36,37}$ and perhaps any serious comorbidity, is likely to worsen prognosis. Furthermore, personality disorders compromise social and occupational functioning independently of depression. ${ }^{38}$ For this reason, we did not consider socioeconomic status as a baseline moderating variable: socioeconomic status is an outcome of personality disorder and, indeed, was lower at baseline in subjects with personality disorders (mean Hollingshead ${ }^{39}$ socioeconomic status scores: MDD/PD-R 3.1 [SD = 1.1], MDD/ PD-NR 3.4 [1.1]) than in subjects with MDD/noPD (2.8 [0.9]). Poor social functioning is likely to generate negative life events, which may then predispose to depressive episodes in vulnerable individuals. ${ }^{40}$

Nonetheless, the majority of treatment studies of MDD have ignored Axis II. Others may have obliquely excluded them by excluding proxies for personality disorders such as suicidality and substance abuse. One might speculate that this reflects the investigators' lack of interest in personality disorders, or perhaps the temporal and economic burdens of administering interviews for Axis II. Yet, if, as 


\begin{tabular}{|c|c|c|c|c|c|c|c|c|c|c|c|c|}
\hline \multirow[b]{4}{*}{ Variable } & & & & \multicolumn{9}{|c|}{ Model Information } \\
\hline & & & & \multicolumn{3}{|c|}{ Group } & \multicolumn{3}{|c|}{ Time } & \multicolumn{3}{|c|}{ Group-by-Time } \\
\hline & \multicolumn{3}{|c|}{ Model-Based Estimated Mean (SE)* } & Test & & & Test & & & Test & & \\
\hline & MDD/noPD & MDD/PD-R & MDD/PD-NR & Result & df & $\mathrm{p}$ & Result & df & $\mathrm{p}$ & Result & df & $\mathrm{p}$ \\
\hline \multicolumn{4}{|l|}{ Employment } & 14.94 & 2,288 & $<.0001$ & 49.88 & 3,514 & $<.0001$ & & & NS** \\
\hline 0 mo & $2.89(0.12)^{\mathrm{A}}$ & $3.20(0.13)^{\mathrm{B}}$ & $3.60(0.10)^{\mathrm{C}}$ & & & & & & & & & \\
\hline $6 \mathrm{mo}$ & $1.92(0.12)$ & $2.23(0.14)$ & $2.63(0.11)$ & & & & & & & & & \\
\hline $12 \mathrm{mo}$ & $1.73(0.12)$ & $2.04(0.14)$ & $2.44(0.11)$ & & & & & & & & & \\
\hline \multirow{2}{*}{\multicolumn{4}{|c|}{ Friend }} & & & & & & & & & \\
\hline & & & & 36.87 & 2,333 & $<.0001$ & 23.32 & 3,333 & $<.0001$ & & & NS \\
\hline 0 mo & $2.47(0.10)^{\mathrm{A}}$ & $2.91(0.12)^{\mathrm{B}}$ & $3.44(0.08)^{\mathrm{C}}$ & & & & & & & & & \\
\hline $6 \mathrm{mo}$ & $2.27(0.10)$ & $2.71(0.12)$ & $3.24(0.09)$ & & & & & & & & & \\
\hline $12 \mathrm{mo}$ & $2.14(0.10)$ & $2.58(0.12)$ & $3.11(0.08)$ & & & & & & & & & \\
\hline $24 \mathrm{mo}$ & $1.91(0.10)$ & $2.35(0.12)$ & $2.88(0.08)$ & & & & & & & & & \\
\hline \multicolumn{4}{|l|}{ Spouse } & 9.45 & 2,127 & $<.0001$ & 3.26 & 3,244 & .0223 & & & NS \\
\hline 0 mo & $2.48(0.19)^{\mathrm{A}}$ & $2.52(0.23)^{\mathrm{B}}$ & $3.30(0.15)^{\mathrm{C}}$ & & & & & & & & & \\
\hline $6 \mathrm{mo}$ & $2.28(0.19)$ & $2.32(0.23)$ & $3.10(0.15)$ & & & & & & & & & \\
\hline $12 \mathrm{mo}$ & $2.20(0.19)$ & $2.23(0.24)$ & $3.02(0.15)$ & & & & & & & & & \\
\hline $24 \mathrm{mo}$ & $1.99(0.20)$ & $2.03(0.24)$ & $2.82(0.16)$ & & & & & & & & & \\
\hline \multicolumn{4}{|l|}{ Parent } & 10.88 & 2,311 & $<.0001$ & 6.96 & 3,311 & .0002 & & & NS \\
\hline 0 mo & $2.40(0.11)^{\mathrm{A}}$ & $2.72(0.13)^{\mathrm{B}}$ & $2.97(0.10)^{\mathrm{B}}$ & & & & & & & & & \\
\hline $6 \mathrm{mo}$ & $2.29(0.10)$ & $2.62(0.12)$ & $2.86(0.09)$ & & & & & & & & & \\
\hline $12 \mathrm{mo}$ & $2.17(0.10)$ & $2.50(0.12)$ & $2.75(0.08)$ & & & & & & & & & \\
\hline $24 \mathrm{mo}$ & $2.09(0.10)$ & $2.42(0.12)$ & $2.66(0.09)$ & & & & & & & & & \\
\hline \multicolumn{4}{|l|}{ Recreation } & 50.25 & 2,333 & $<.0001$ & 32.49 & 3,969 & $<.0001$ & & & NS \\
\hline 0 mo & $2.91(0.09)^{\mathrm{A}}$ & $3.15(0.10)^{\mathrm{B}}$ & $3.81(0.07)^{\mathrm{C}}$ & & & & & & & & & \\
\hline $6 \mathrm{mo}$ & $2.41(0.09)$ & $2.65(0.10)$ & $3.31(0.07)$ & & & & & & & & & \\
\hline $12 \mathrm{mo}$ & $2.30(0.09)$ & $2.54(0.10)$ & $3.19(0.08)$ & & & & & & & & & \\
\hline $24 \mathrm{mo}$ & $2.10(0.09)$ & $2.34(0.10)$ & $3.00(0.08)$ & & & & & & & & & \\
\hline \multicolumn{4}{|l|}{ Social } & 48.65 & 2,333 & $<.0001$ & 68.88 & 3,333 & $<.0001$ & 6.89 & 6,333 & $<.0001$ \\
\hline $0 \mathrm{mo}$ & $3.41(0.08)^{\mathrm{A}}$ & $3.99(0.08)^{\mathrm{B}}$ & $4.08(0.07)^{\mathrm{B}}$ & & & & & & & & & \\
\hline $6 \mathrm{mo}$ & $2.88(0.10)^{\mathrm{A}}$ & $3.00(0.12)^{\mathrm{A}}$ & $3.77(0.08)^{\mathrm{B}}$ & & & & & & & & & \\
\hline $12 \mathrm{mo}$ & $2.76(0.10)^{\mathrm{A}}$ & $3.00(0.12)^{\mathrm{A}}$ & $3.79(0.08)^{\mathrm{B}}$ & & & & & & & & & \\
\hline $24 \mathrm{mo}$ & $2.65(0.10)^{\mathrm{A}}$ & $2.73(0.12)^{\mathrm{A}}$ & $3.66(0.08)^{\mathrm{B}}$ & & & & & & & & & \\
\hline \multicolumn{4}{|l|}{ GAF } & 48.27 & 2,333 & $<.0001$ & 43.86 & 3,333 & $<.0001$ & 5.96 & 6,333 & $<.0001$ \\
\hline 0 mo & $61.01(0.93)^{\mathrm{A}}$ & $55.30(1.13)^{\mathrm{B}}$ & $52.41(0.73)^{\mathrm{B}}$ & & & & & & & & & \\
\hline $6 \mathrm{mo}$ & $66.52(1.11)^{\mathrm{A}}$ & $63.54(1.35)^{\mathrm{B}}$ & $55.19(0.87)^{\mathrm{C}}$ & & & & & & & & & \\
\hline $12 \mathrm{mo}$ & $67.42(1.15)^{\mathrm{A}}$ & $63.32(1.40)^{\mathrm{B}}$ & $55.03(0.91)^{\mathrm{C}}$ & & & & & & & & & \\
\hline $24 \mathrm{mo}$ & $65.60(1.27)^{\mathrm{A}}$ & $65.20(1.44)^{\mathrm{A}}$ & $53.46(1.00)^{\mathrm{B}}$ & & & & & & & & & \\
\hline \multicolumn{13}{|c|}{$\begin{array}{l}\text { *Different superscripts denote groups that have statistically significantly different means; same superscript denotes that the groups do not have } \\
\text { significantly different means. When the group-by-time interaction is not statistically significant, differences between the groups are the same } \\
\text { at all time points. If baseline relationships did not change, superscripts have not been repeated at subsequent time points. } \\
\text { ** Model information reports results from the main effect model when there is no statistically significant group-by-time interaction. } \\
\text { Abbreviations: GAF = Global Assessment of Functioning, LIFE = Longitudinal Interval Follow-up Evaluation, MDD/noPD = major } \\
\text { depressive disorder without comorbid personality disorder, MDD/PD-NR = major depressive disorder with nonremitted personality } \\
\text { disorder, MDD/PD-R = major depressive disorder with remitted personality disorder. }\end{array}$} \\
\hline
\end{tabular}

our findings using state-of-the-art instruments indicate, the presence of Axis II diagnoses moderates Axis I MDD symptomatic and functional outcome, the omission of Axis II diagnoses is a serious one.

We conclude that comorbid personality disorders matter for patients with MDD and that the clinical course of these disorders directly influences outcome. Personality disorders represent a chronic burden on patients that extends beyond suffering from symptoms to impairments in interpersonal and social domains. In targeting the optimal outcome for patients with major depressive disorders, clinicians should consider whether a personality disorder may be complicating the clinical picture and design a treatment plan in that light. A common strategy has been to first treat Axis I disorders like MDD and see whether Axis II features fade as MDD improves. Yet, Gunderson et al. ${ }^{41}$ found that in patients with comorbid MDD and borderline personality disorder, remission of borderline personality disorder was more likely to precede MDD remission than the reverse. Ignoring Axis II diagnoses should become ever more difficult in view of recent findings that personality disorders respond to treatment in controlled $^{42-44}$ and naturalistic ${ }^{10,45,46}$ settings. More research should be devoted to finding effective treatments for personality disorders. Moreover, clinicians should consider functional as well as symptomatic improvement. The social functioning aspects of personality disorders deserve particular attention and treatment.

\section{REFERENCES}

1. Judd LL, Akiskal HS, Zeller PJ, et al. Psychosocial disability during the long-term course of unipolar major depressive disorder. Arch Gen 
Psychiatry 2000;57:375-380

2. Ormel J, von Korff M, van den Brink W, et al. Depression, anxiety, and social disability show synchrony of change in primary care patients. Am J Pub Health 1993;83:385-390

3. Ormel J. Synchrony of change in depression and disability: what next? Arch Gen Psychiatry 2000;57:381-382

4. Skodol AE, Pagano ME, Bender DS, et al. Stability of functional impairment in patients with schizotypal, borderline, avoidant, or obsessive-compulsive personality disorder over two years. Psychol Med 2005;35:443-451

5. Weissman MM, Klerman GL, Prusoff BA, et al. Depressed outpatients: results one year after treatment with drugs and/or interpersonal psychotherapy. Arch Gen Psychiatry 1981;38:51-55

6. Weissman MM, Markowitz JC, Klerman GL. Comprehensive Guide to Interpersonal Psychotherapy. New York, NY: Basic Books; 2000

7. Ormel J, Odldehinkel AJ, Nolen WA, et al. Psychosocial disability before, during, and after a major depressive episode: a 3-wave population-based study of state, scar, and trait effects. Arch Gen Psychiatry 2004;61:387-392

8. Hays RD, Wells KB, Sherbourne CD, et al. Functioning and well-being outcomes of patients with depression compared with chronic general medical illnesses. Arch Gen Psychiatry 1995;52:11-19

9. Skodol AE, Grilo CM, Pagano ME, et al. Effects of personality disorders on functioning and well-being in major depressive disorder. J Psychiatr Pract 2005;11:363-368

10. Grilo CM, Sanislow CA, Gunderson JG, et al. Two-year stability and change of schizotypal, borderline, avoidant, and obsessive-compulsive personality disorders. J Consult Clin Psychol 2004;72:767-775

11. Zanarini MC, Frankenburg FR, Hennen J, et al. Psychosocial functioning of borderline patients and axis II comparison subjects followed prospectively for six years. J Personal Disord 2005; 19:19-29

12. Lenzenweger MF, Johnson MD, Willet JB. Individual growth curve analysis and change in personality disorder features: the longitudinal study of personality disorders. Arch Gen Psychiatry 2004;61:1015-1024

13. Johnson JG, Cohen P, Kasen S, et al. Age-related change in personality disorder trait levels between early adolescence and adulthood: a community-based longitudinal investigation. Acta Psychiatr Scand 2000;102: 265-275

14. Grilo CM, Sanislow CA, Shea MT, et al. Two-year prospective naturalistic study of remission from major depressive disorder as a function of personality disorder comorbidity. J Consult Clin Psychol 2005;73:78-85

15. First MB, Gibbon M, Spitzer RL, et al. Structured Clinical Interview for DSM-IV Axis I Disorders-Patient Version (SCID-I/P). New York, NY: Biometric Research, New York State Psychiatric Institute; 1996

16. Zanarini MC, Frankenburg FR, Sickel AE, et al. The Diagnostic Interview for DSM-IV Personality Disorders (DIPD-IV). Belmont, Mass: McLean Hospital, Laboratory for the Study of Adult Development; 1996

17. McGlashan TH, Grilo CM, Skodol AE, et al. The Collaborative Longitudinal Personality Disorders Study: baseline Axis I/II and II/II diagnostic co-occurrence. Acta Psychiatr Scand 2000;102:256-264

18. Bender DS, Dolan RT, Skodol AE, et al. Treatment utilization by patients with personality disorders. Am J Psychiatry 2001;158:295-302

19. Keller MB, Lavori PW, Friedman B, et al. The Longitudinal Interval Follow-up Evaluation: a comprehensive method for assessing outcome in prospective longitudinal studies. Arch Gen Psychiatry 1987;44: $540-548$

20. Zanarini MC, Skodol AE, Bender D, et al. The Collaborative Longitudinal Personality Disorders Study: reliability of axis I and II diagnoses. J Personal Disord 2000;14:291-299

21. Warshaw MG, Keller MB, Stout RL. Reliability and validity of the Longitudinal Interval Follow-up Evaluation for assessing outcome of anxiety disorders. J Psychiatr Res 1994;28:531-545

22. American Psychiatric Association. Diagnostic and Statistical Manual of Mental Disorders, Fourth Edition, Text Revision (DSM-IV-TR).
Washington, DC: American Psychiatric Association; 2000

23. Gunderson JG, Shea MT, Skodol AE, et al. The Collaborative Longitudinal Personality Disorders Study: development, aims, design, and sample characteristics. J Personal Disord 2000;14:300-315

24. Hosmer DW, Lemeshow S. Applied Survival Analysis: Regression Modeling of Time to Event Data. New York, NY: Wiley; 1998

25. Liang KY, Zeger SL. Longitudinal data analysis using generalized linear models. Biometrika 1986;73:13-22

26. Kass RE, Raftery AE. Bayes factors. J Am Stat Assoc 1993;90:773-795

27. Wolfinger RD. Covariance structure selection in general mixed models. Commun Stat Simul Comput 1993;22:1079-1106

28. Warner MB, Morey LC, Finch JF, et al. The longitudinal relationship of personality traits and disorders. J Abnorm Psychol 2004;113:217-227

29. Mulder RT. Personality pathology and treatment outcome in major depression: a review. Am J Psychiatry 2002;159:359-371

30. Newton-Howes G, Tyrer P, Johnson T. Personality disorder and the outcome of depression: meta-analysis of published studies. Br J Psychiatry 2006;188:13-20

31. Duggan CF, Lee AS, Murray RM. Does personality predict long-term outcome in depression? Br J Psychiatry 1990;157:19-24

32. Zuckerman DM, Prusoff BA, Weissman MM, et al. Personality as a predictor of psychotherapy and pharmacotherapy outcome for depressed outpatients. J Consult Clin Psychol 1980;48:730-735

33. Mulder RT, Joyce PR, Frampton CM, et al. Six months of treatment for depression: outcome and predictors of course of illness. Am J Psychiatry 2006; $163: 95-100$

34. Reich J. The effect of Axis II disorders on the outcome of treatment of anxiety and unipolar depressive disorders: a review. J Personal Disord 2003:17:387-405

35. Shea MT, Pilkonis PA, Beckham E, et al. Personality disorders and treatment outcome in the NIMH Treatment of Depression Collaborative Research Program. Am J Psychiatry 1990;147:711-718

36. Brown C, Schulberg HC, Madonia MJ, et al. Treatment outcomes for primary care patients with major depression and lifetime anxiety disorders. Am J Psychiatry 1996;153:1293-1300

37. Frank E, Shear MK, Rucci P, et al. Influence of panic-agoraphobic spectrum symptoms on treatment response in patients with recurrent major depression. Am J Psychiatry 2000;157:1101-1107

38. Skodol AE, Gunderson JG, McGlashan TH, et al. Functional impairment in patients with schizotypal, borderline, avoidant, or obsessivecompulsive personality disorder. Am J Psychiatry 2002;159:276-283

39. Hollingshead AB, Redlich FC. Social Class and Mental Illness: A Community Study. New York, NY: Wiley; 1958

40. Klerman GL, Weissman MM, Rounsaville BJ, et al. Interpersonal Psychotherapy of Depression. New York, NY: Basic Books; 1984

41. Gunderson JG, Morey LC, Stout RL, et al. Major depressive disorder and borderline personality disorder revisited: longitudinal interactions. J Clin Psychiatry 2004;65:1049-1056

42. Linehan MM, Heard HL, Armstrong HE. Naturalistic follow-up of a behavioral treatment for chronically parasuicidal borderline patients Arch Gen Psychiatry 1993;50:971-974

43. Bateman A, Fonagy P. Treatment of borderline personality disorder with psychoanalytically oriented partial hospitalization: an 18-month followup. Am J Psychiatry 2001;158:36-42

44. Svartberg M, Stiles TC, Seltzer MH. Randomized, controlled trial of the effectiveness of short-term dynamic psychotherapy and cognitive therapy for cluster C personality disorders. Am J Psychiatry 2004;161:810-817

45. Shea MT, Sout R, Gunderson J, et al. Short-term diagnostic stability of schizotypal, borderline, avoidant, and obsessive-compulsive personality disorders. Am J Psychiatry 2002;159:2036-2041

46. Zanarini MC, Frankenburg FR, Hennen J, et al. The longitudinal course of borderline psychopathology: 6-year prospective follow-up of the phenomenology of borderline personality disorder. Am J Psychiatry 2003; 160:274-283 